\title{
Research on Characteristics of Real Estate Price Bubbles in China
}

\author{
Minyi $\mathrm{Yu}^{1, \mathrm{a}^{*}}$ and Chunjie Ma $\mathrm{M}^{1, \mathrm{~b}}$ \\ ${ }^{1}$ College of Civil Engineering and Architecture, Zhejiang University, China \\ a21412006@zju.edu.cn, b13905742430@139.com
}

Keywords: Real estate price bubbles; Price earnings ratio; Tripartite game; GDP growth rate

\begin{abstract}
To illustrate the Chinese real estate market bubbles' situation and trends, analyze relevant characteristics and structural features, this research used qualitative and quantitative research methods, and focused on statistical analysis of housing prices in major cities and the whole country, like the growth rate of economic and price, the price earnings ratio and other data. Basing on the relevant literature at home and abroad, this results showed that there is a small deviation of China's overall economic development and the real estate index, individual cities is relatively large but still acceptable. Chinese real estate market bubble is not serious, because of irrational economic growth, super city agglomeration effect, short-sighted real estate regulations and deformity housing concept, consumers would feel house price is too high.
\end{abstract}

\section{Introduction}

In the late 1980s, the concept of real estate bubble is recognized by academia, these typical cases are including real estate bubbles in Singapore, Malaysia, Thailand, Hong Kong, China and other South East Asia in the 1990s. Kindleberger defined bubble as a state, one or a series of assets in a continuous process of sharp price increases, prices begin to rise while there is still an expectation of rising, so it could attract new buyers, these buyers want to make a profit by buying and selling, while assets themselves are not interested in the use and profitability. As prices rise, people's expectations will change, the greater the magnitude of the price rise, the more buyers who are expected to produce reversible reaction. When a substantial increase in the number of expected buyers and reaches a certain level, the price fall will occurs, ends in the form of the financial crisis [1]. Real estate, especially the increase in housing prices has significant short-term impact on the economy, which could keep home sales strong, gradually encourage consumer spending, so to maintain an appropriate bubble in promoting economic development has a positive effect. However, real estate price bubble appear means a negative effects mostly [2].

Once the bubble burst, it results in the loss of housing wealth, there are two ways of the economic slowdown, one is housing investment derailment, and the other is an impact on consumption through the wealth effect [3]. The owner of the house is almost close to the minimum net assets recorded of if the bubble bursts, this will make an important support of consumption disappear. Finally, the real estate bubble burst sets fire to the whole region and even the country's economy recession $[4,5]$.

\section{Situation and Trends}

When there is a rapid expansion of real estate, in order to illustrate the extent of bubble, it's usually used the extent of deviation of the economic development indicators (real estate price growth rate / GDP growth), It is generally believed that the index is greater than 3 means the real estate bubble occurs, this is a simple and practical indicator to measure the real estate bubble. Fig. 1 shows the National Bureau of Statistics data. 


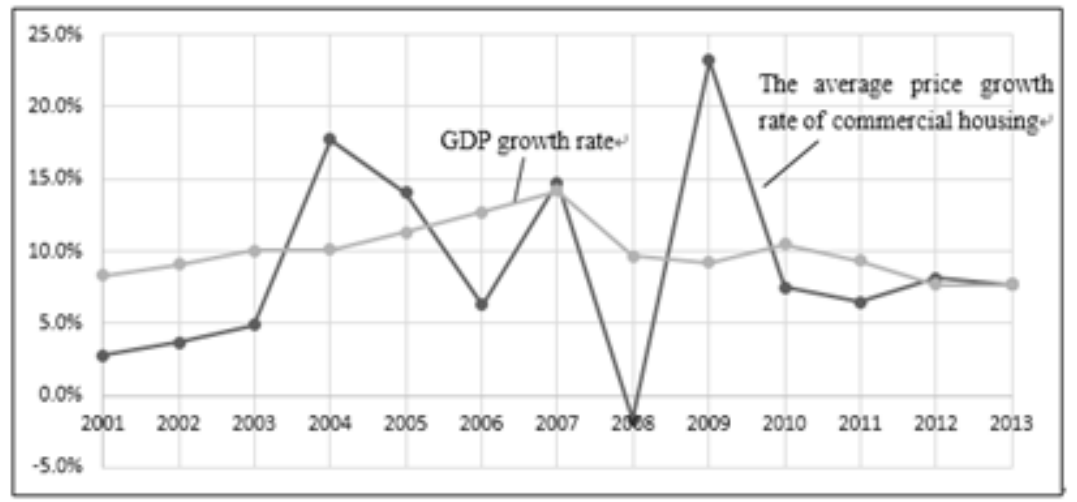

Figure 1. The average price growth rate of commercial housing and GDP growth rate of China

From the graph above we can find, according to the National Bureau of Statistics, the value of the national real estate sales price growth divides the ratio of the average GDP growth rate is small. Preliminary analysis of the reasons, China is a vast country, nationwide housing price growth relative to GDP growth is actually acceptable, which is why some scholars do not accept that the Chinese real estate market bubble is serious.

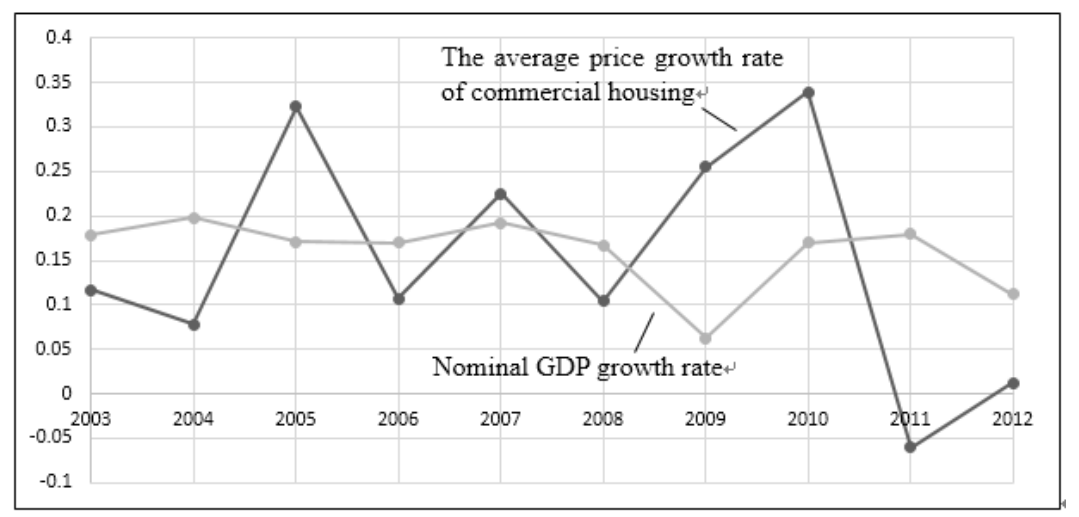

Figure 2. The average price growth rate of commercial housing and nominal GDP growth rate of Hangzhou

Nationwide statistics reference value does not match with ordinary people's actual feelings, take Hangzhou as an example, compared the average selling price of commercial housing with the GDP growth rate to illustrate the overall status of the real estate price bubble. It can be found in Hangzhou area real estate price growth is not very prominent far from the average nominal GDP growth rate. The reason comes from two aspects, one is Hangzhou as an important city in the Yangtze River Delta, in the past decade economy this area has achieved growth rates higher than the national real estate development, on the other hand, the house prices of Hangzhou is adapt to their economic development, although there is a certain high degree. The most important reason is as described above, there is a higher wealth gap between regions and the flow speeds up also improves the general public psychological feelings on the real estate prices.

There is also a description of the real estate bubble, which is the price earnings ratio [6]. Price earnings ratio is the ratio of housing prices and household income of urban residents [7]. Nationwide, the same with the average sales price growth rate and GDP growth rate shows, the domestic real estate bubble does not expect serious. In 1998, Beijing current average annual household income is equivalent to 12 countries, the price earnings ratio is 2.1 to 20 , the mean and median is 9 and 8.1. Under this comparison, Beijing's price earnings ratio is roughly equal to the average level of these countries. Prevailing 3-6 times of the ratio of is lack of research, it does not have enough convincing. 


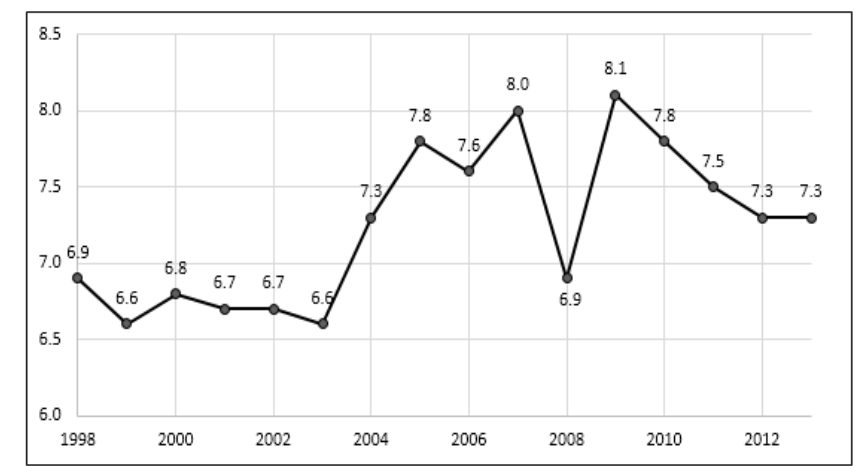

Figure 3. Price earnings ratio of China(1998-2013)

Hangzhou, for example, with the price earnings ratio to illustrate the extent of the real estate market bubble. The results showed that this ratio was significantly higher compared to other foreign countries. According to Real Estate Industry Association of Zhejiang Province and Zhejiang University Real Estate Research Center jointly issued the "First Half of 2013, Zhejiang Province, Real Estate Development Report", the report shows, 11 prefecture-level city in Zhejiang that price earnings ratio is above 8, Wenzhou and Hangzhou are highest respectively 27.8 and 21.2 , namely in Wenzhou, a family of three working families, need to not eat or drink for nearly 28 years to afford a set of 90 square meters of housing, even normal living expenses is removed, the payment process is still long. That is, there are more market speculations of the region, which is crueler than the nation.

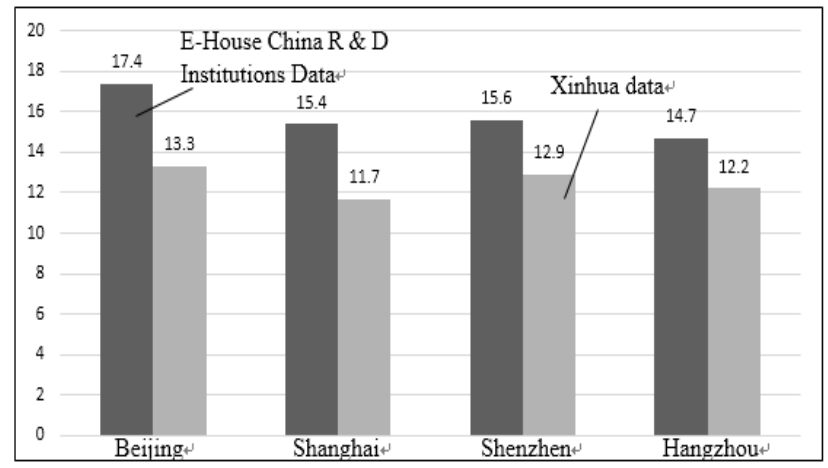

Figure 4. Price earnings ratio of China's major cities in 2013

\section{Characteristics of Real Estate Price Bubbles}

Case and Shiller believed that the concept of bubble is from the people actually thought, expectations of future price increases, insights of the price downside risk, and concerns about driven out by market [8]. Expand the following analysis of consumer and investor psychology and behavior, the characteristics of Chinese real estate price bubble will be described.

Irrational economic growth. December 9, 2012, Survey Research Center, China Household Financial and Southwest University of Finance to complete the implementation of "Family Income Inequality in China Report" released publicly, China's Gini coefficient of household income up to 0.61, the Gini coefficient of urban households was 0.56, the rural family's Gini coefficient was 0.60, but according to the World Bank data, in 2010 the global average Gini coefficient is 0.44, indicating that China's huge income gap. In addition, the income gap between urban and rural areas is also very large, between regions might larger.

The one hand, economic growth in the past, the construction of infrastructure is as the driving force, the construction industry and related industries are benefit from the first national economic policy adjustment, due to the construction and capital-intensive industry, the current ordinary income is in stark contrast. On the one hand, the national economy as a whole for the better, but there is a certain 
amount of inflation, currency depreciate gradually over time, so that the first benefit group have strong investment demand, the domestic financial industry is not developed, financial products available for investment is less, a lot of these funds will flow away to the real estate industry, resulting in a rapid growth of real estate prices.

Super city agglomeration effect. "Cluster effect" refers to a variety of industrial and economic effect on the spatial concentration of economic activities and to attract economic activity generated by the centripetal force to close certain areas, it is an essential factor leading to the formation of cities and expanding. Urban agglomeration of production factors influence on housing prices increase, even though consumption and accumulation agglomeration growing influence is essentially the same, structural optimization and complete set of influence increases, that is the late stage of development of urban agglomeration process of urbanization on prices plays the major supporting role.

Beijing, for example, a large number of population, resources, and funds have continued to gather in Beijing, high-income groups continue to migrate, but also because it is the country's political and cultural center, radiation nationwide coverage in China's unique form of society, most people will seek pillar in Beijing, the Beijing housing prices have contributed to these increases. Other domestic cities generally have characteristic region's political, economic and cultural center of the area so that housing prices continue to rise [9].

Short-sighted real estate regulations. "Real estate regulations," the purpose is not only to maintain a healthy and sustainable development of the real estate market, but also more importantly, in order to maintain sustainable economic development. Government regulations of real estate will directly affect the real estate trends.

August 2003, the State Council explicitly the real estate industry as a pillar industry of the national economy, "The Real Estate Market on the Promotion of Sustained and Healthy Development," the real estate industry will be one of the pillar industries of the national economy pulling positioning development, clearly to maintain the sustained and healthy development of real estate, to fully understand the requirements of real estate, which marking the rapid rise of real estate. In March 2005, country eight issued the regulation up to the political height (old country eight), the State Council issued eight opinions to stable prices, which marking the real estate industry from a closed die, a place on the chaos of endless loop. Then in 2008 bailout of real estate into a lot of money, and then it is contracted to a new term for the real estate industry when leaders take the form of cold treatment, then it does not fall into an infinite loop.

Deformity housing concept. At present, China 9/10 families own their own homes, compared to only about two-thirds in the United States. This data indicates that to a certain extent, in past generations, even the very limited financial resources of Chinese young people are about to dream to have their own homes. For many of today's Chinese people, to buy a house remains a key first step of getting married. Homeownership for the Chinese people's sense of security is so important and make a lot of "house slaves" (referring to those who still have to continue to do the work and live they may not like to meet their own mortgage) appears.

Young people eager to buy a house, partly because of the deformity concept housing, as well partly because the rental market is still not standardized, except for a few cities, the rental market is mature. While there are a considerable part of the market is still in early stages of development. More importantly, the young people to buy more than is derived from insecurity, social and future expectations is not confident, it also required a long time to change.

\section{Structure of China's Real Estate Market}

China's real estate market constitutes is a special existence, as the country's economic development, the government is playing an increasingly important role in the development of real estate, and also almost determined the development of the whole industry in a period [10,11]. Later, with the more reasonable regulation of the national economy, the China's real estate market constitute keeps the 
basic trend as shown in Fig. 5, the dynamic process of government, real estate related businesses and the general consumers' tripartite game.

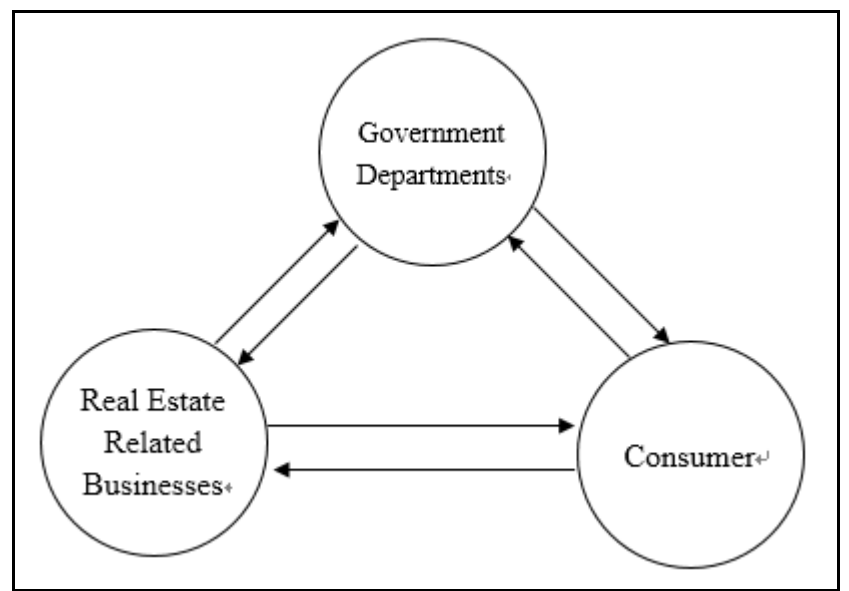

Figure 5. The structure of China's real estate market

Simply put, this country's economic development is still a great need to support the real estate industry, real estate industry has been kidnapped stability of the country, and can be in exchange position in the industry, a stable real estate for the stability of our country with incalculable meaning. Real estate companies need to communicate more with the general population, in order to achieve the public good expectations for the real estate industry in the future. Government in the past has served as the leading sector, participated in too many real estate transactions, and now need to gradually withdraw from the market, no longer allow itself to be bound by the real estate industry, on the other hand, for the government, to give the public a satisfactory process and establish a government authority has greater significance. Of course, for the people, it will continue to benefit from dynamic adjustment, the people only react according to the market situation in most cases based on their own interests. People need to make a choice among many real estate companies, find out the higher comprehensive appraisal of the real estate business, and continue to exert the necessary pressure to the government so that the development of the market is conducive to the future development of the multi-target, then into a virtuous cycle of the real estate market.

Actually, the most fundamental paradox of China's real estate market is that the government acquires the real estate market's most of the revenue, land transfer profitable, relevant tax profitable, housing construction, sale process all could make a profit. In the supply-demand balance of the market, with the process of urbanization across the country, the existing stock of housing is still unable to meet a large number of rural population into urban population needs. However, most of the value created by the people is excessively consumed by government in real estate market, the supply and demand balance is broken by the government involved in the expansion, which causes the high price of real estate that people psychological feelings. All in all, the government, real estate related businesses and the general consumers' tripartite game is played well, real estate market goes well.

\section{Conclusions}

For real estate companies, the future must be a painful time for the mismanagement of small and medium enterprises, even most likely to face the risk of failure. How to improve management and efficiency, to survive in the new market environment is the main consideration for the current real estate business. For the government, continue to reduce government intervention in the market, and strive to narrow down the income gap, shift focus, efforts to adjust the economic structure of the economy towards the positive direction, only the other well, and then the real estate market can really form a good regulation. Also, the government should try to solve the problem of land, efforts to lay the foundation for stable development of the market. For ordinary residents, no need to panic about the 
future real estate market, according to personal consumption ability to meet the housing problem is fine, do not need to worry about the risk of excessive prices will fall sharply. The future of China's real estate market, a steady fall in prices, but overall is safe, rigid demand of society will gradually solve the existing housing stock, and rising incomes will gradually fill the gap between income to housing prices, as long as the government no longer goes an excessive intervention, the real estate market will gradually toward a healthy direction.

\section{References}

[1] Kindleberger, Charles P. "Manias, panics, and crashes: a history of financial crises." The Scriblerian and the Kit-Cats 32.2 (2000): 379.

[2] Case, Karl E., John M. Quigley, and Robert J. Shiller. "Comparing wealth effects: the stock market versus the housing market." advances in Macroeconomics 5.1 (2005).

[3] Himmelberg, Charles, Christopher Mayer, and Todd Sinai. Assessing high house prices: Bubbles, fundamentals, and misperceptions. No. w11643. National Bureau of Economic Research, 2005.

[4] Glaeser, Edward L., Joseph Gyourko, and Albert Saiz. "Housing supply and housing bubbles." Journal of urban Economics 64.2 (2008): 198-217.

[5] Hui, Eddie CM, and Shen Yue. "Housing price bubbles in Hong Kong, Beijing and Shanghai: a comparative study." The Journal of Real Estate Finance and Economics 33.4 (2006): 299-327.

[6] Abraham, Jesse M., and Patric H. Hendershott. Bubbles in metropolitan housing markets. No. w4774. National Bureau of Economic Research, 1994.

[7] Ou, Jane A., and Stephen H. Penman. "Accounting measurement, price-earnings ratio, and the information content of security prices." Journal of Accounting Research (1989): 111-144.

[8] Case, Karl E., and Robert J. Shiller. "Is there a bubble in the housing market?." Brookings Papers on Economic Activity 2003.2 (2003): 299-362.

[9] Wu, W. J., et al. "Tempo-spatial analysis of the residential land's spatial pattern in Beijing." Geographical Research 29.4 (2010): 683-692.

[10] Wu, Fulong. "Real estate development and the transformation of urban space in China's transitional economy, with special reference to Shanghai." The new Chinese city: Globalization and market reform (2002): 153-166.

[11]Guo, Feng, and Ying Sophie Huang. "Does "hot money" drive China's real estate and stock markets?." International Review of Economics \& Finance 19.3 (2010): 452-466. 